\section{Emergence and Seedling Growth of Okra Genotypes at Low Temperatures}

\author{
Lurline Marsh ${ }^{1}$ \\ Department of Agriculture, Natural Resources and Home Economics, \\ Lincoln University, Jefferson City, MO 65102-0029
}

Additional index words. Abelmoschus esculentus

\begin{abstract}
Seedling emergence and growth of 39 genotypes of okra [ Abelmoschus esculentus (L.) Moench] were studied at several temperatures. Seeds were evaluated in two separate studies. One was a 3-year early planting field evaluation where air temperatures ranged from -2 to $29 \mathrm{C}$. The other was a study at controlled temperatures of $10 / 10,14 / 10,15 / 15,20 / 10$, and $20 / 20 \mathrm{C}$ day/night. Okra genotypes showed variation in seedling emergence in the field, but the results fluctuated over years. Seedlings emerged at all the controlled temperatures, although the percentage of emergence reached only $13 \%$ at $10 / 10 \mathrm{C}$. All temperature regimes produced some degree of leaf chlorosis, the severity of which was greatest at the lower temperatures. Leaves of none of the okra seedlings of any of the genotypes grew at 10/10, 14/10, or 15/15C. Genotypic variation in emergence was observed with the controlled temperatures.
\end{abstract}

Okra is sensitive to chilling temperatures and grows poorly below $15 \mathrm{C}$, which climatically constrains its production. Seedlings at the five-leaf stage that were chilled at 10C for $144 \mathrm{~h}$ had notable external leaf damage (Omran, 1969). Sionit et al. (1981) reported seed germination for 'Clemson Spineless' okra at 17/11, 20/14, and 23/17C day/night, with the lower temperatures delaying emergence. They also found that mature okra plants could not be produced below 26/20C unless the air was CO, enriched. Robbins (1982) recommended that soil temperatures be $\approx 18 \mathrm{C}$ before planting.

No information appears to be available on the variability of okra germplasm in germination and seedling growth at temperatures in the range 10-20C. Cotton (Gossypium hirsutum L.), which also belongs to the Malvaceae, has significant cultivar variability for seed germination at low temperature (Buxton and Sprenger, 1976). Information on the effect of low temperatures on okra will be useful in developing cultivars able to withstand relatively low temperatures. Cultivars that can withstand cooler soils will facilitate earlier plantings and extend the growing season in temperate regions. This study was conducted to evaluate okra germplasm for its variability in emergence and seedling growth at low temperatures.

Emergence and seedling growth of $36 \mathrm{okra}$ plant introductions and three cultivars,

Received for publication 8 Nov. 1991. Accepted for publication 28 May 1992. Journal paper no. E6-212-91 of the Lincoln Univ. Agricultural Experiment Station. Trade names are mentioned with the understanding that no discrimination is intended and no endorsement by the authors or Lincoln Univ. is implied. Research supported in part by USDA-CSRS funds allocated to the Univ. Agricultural Experiment Station. The cost of publishing this paper was defrayed in part by the payment of page charges. Under postal regulations, this paper therefore must be hereby marked advertisement solely to indicate this fact.

${ }^{1}$ Associate Professor.
Clemson Spineless, Clemson Spineless 80, and Candelabra Branching, were evaluated in early field plantings and in a controlledtemperature study comprising five temperature regimes. Plant introductions were obtained from the Southern Regional Plant Introduction Station, Experiment, Ga.

Field evaluations were conducted at Lincoln Univ.'s Greenberry Farm (soil-type Elk silt loam, Ultic Hapludult, $\mathrm{pH}$ 6.5) where seeds were hand planted in single-row plots on 17 Apr. 1986, 23 Apr. 1987, and 1.5 Apr. 1988. Seeds were placed $\approx 4 \mathrm{~cm}$ deep, 7.5 $\mathrm{cm}$ apart in 4.7-m long rows spaced $0.9 \mathrm{~m}$ apart. The design for each year was completely randomized, with three replications. Analysis of variance was done separately for each year because the number of genotypes differed in one year from the others and because of germination failure of several genotypes in another year. Mean differences were determined by Fisher's least significant difference (LSD). Seedling emergence as determined by the emergence of the cotyledons above the soil was measured daily for the first 21 days after planting and periodically between 21 and 32 days.

Soil temperatures at an 8-cm depth and air temperatures were monitored by Weathertronic (Qualimetric, Sacramento, Calif.) remote three-point thermographs and Cole Parmer (Cole Parmer, Chicago) hygrothermographs, respectively. The soil and air temperatures and the combined rainfall and irrigation for the first 21 days after planting were recorded (Table 1).

The controlled-temperature study was done

Table 1. Field temperature and precipitation during 21 days following okra planting over 3 years.

\begin{tabular}{|c|c|c|c|c|c|c|c|c|c|}
\hline \multirow[b]{3}{*}{ Year } & \multicolumn{4}{|c|}{ Soll temp (־) } & \multicolumn{4}{|c|}{ Air temp ("L) } & \multirow{3}{*}{$\begin{array}{l}\text { Precipitation } \\
\text { (mm) }\end{array}$} \\
\hline & \multicolumn{2}{|c|}{ Day } & \multicolumn{2}{|c|}{ Night } & \multicolumn{2}{|c|}{ Day } & \multicolumn{2}{|c|}{ Night } & \\
\hline & Min & $\operatorname{Max}$ & Min & $\operatorname{Max}$ & $\overline{\operatorname{Min}}$ & $\overline{\operatorname{Max}}$ & Min & $\overline{\operatorname{Max}}$ & \\
\hline 1986 & 12 & 29 & 9 & 24 & ... & 23 & -2 & $\ldots$ & 99 \\
\hline 1987 & 17 & 29 & 9 & 21 & 20 & 29 & 2 & 15 & 58 \\
\hline 1988 & 11 & 28 & 2 & 21 & 11 & 31 & -2 & 25 & 75 \\
\hline
\end{tabular}
ling emergence was recorded daily for the first 21 days when growth data on shoot and root length, number of leaves and roots, and shoot and root dry weight were determined for emerged plants. Shoot length was measured from the surface of the medium to the apical tip of the plant, root length was determined for the main root, and root count was the total for the main plus lateral roots.

Field evaluation of the okra genotypes over the three years showed inconsistent seedling emergence (data not presented). The maximum seedling emergence under these conditions varied from $17 \%$ in one year to $74 \%$ in another. The low degree of field emergence perhaps was due to imbibition chilling injury, such as that reported for cotton (Herner, 1986). Chilling damage of cotton seeds at imbibition causes radicle tip abortion, while chilling after germination causes damage to the root cortex (Christiansen, 1963, 1967).

At the controlled chilling regime of 10/ $10 \mathrm{C}$, seedling emergence of 39 okra genotypes was similar. Only six genotypes-PIs 120836, 175563, 127417, 138508, 357997 , and 'Clemson Spineless'-had any emergence 18 days after planting, and the maximum was $13 \%$ at 21 days after planting. Emerged seedlings from these genotypes were true leaves. The poor emergence at this temperature was similar to that for the 1988 field evaluations in which emergence required 17 days and the maximum was only $17 \%$. The soil and air temperatures in the field at night fell below 10C in 1988 (Table 1).

Okra genotypes showed a range from $0 \%$ in a Conviron (Controlled Environments, Asheville, N.C.) growth chamber having air kept at 10/10, 14/10, 15/15, 20/10, and 20/ $20 \mathrm{C}$ day/night, all $\pm 0.5 \mathrm{C}$. Temperature combinations with $\leq 15 \mathrm{C}$ were selected to represent chilling conditions, and 20/20 represented a low but nonchilling temperature. The planting medium (Promix BX, Premier Brands, Stanford, Conn.) was 1 to $3 \mathrm{C}$ cooler at night than the air. The photoperiod was 14/10 h day/night and provided $450 \mu \mathrm{mol} \cdot \mathrm{m}^{-2} \cdot \mathrm{s}^{-1}$ total radiation at the level of the medium. Seeds were planted in the growing medium at a depth of $\approx 2.5 \mathrm{~cm}$ in plastic flats that then were placed in the growth chamber at the desired temperature. Ten seeds of each genotype were planted for each of three replications. The growing medium was irrigated as necessary. Each temperature regime evaluation was run separately. Each run was conducted as a completely random design with genotypes as treatments. Analyses of variance were done separately for each regime, and Fisher's LSD calculated. Seedpale yellow to whitish and failed to produce 
Table 2. Emergence (percent) of okra genotypes at 21 days after planting at four day/night temperature combinations.

\begin{tabular}{|c|c|c|c|c|}
\hline \multirow{2}{*}{$\begin{array}{l}\text { PI no. or } \\
\text { cultivar }\end{array}$} & \multicolumn{4}{|c|}{ Temp $\left({ }^{\circ} \mathrm{C}\right)$} \\
\hline & \multicolumn{4}{|c|}{$14 / 1015 / 1520 / 1020 / 20$} \\
\hline 120826 & 10 & 50 & 87 & 77 \\
\hline 120836 & 20 & 83 & 90 & 97 \\
\hline 120841 & 3 & 73 & 57 & 83 \\
\hline 124398 & 10 & 67 & 97 & 93 \\
\hline 127417 & 7 & 70 & 87 & 87 \\
\hline 138508 & 40 & 93 & 97 & 90 \\
\hline 140316 & 7 & 87 & 87 & 93 \\
\hline 142781 & 10 & 83 & 93 & 97 \\
\hline 142785 & 7 & 47 & 87 & 77 \\
\hline 167376 & 13 & 83 & 90 & 90 \\
\hline 169693 & 30 & 77 & 67 & 90 \\
\hline 169700 & 37 & 77 & 60 & 93 \\
\hline 169701 & 43 & 80 & 70 & 90 \\
\hline 169712 & 30 & 73 & 63 & 90 \\
\hline 171658 & 13 & 67 & 73 & 83 \\
\hline 171659 & 3 & 80 & 70 & 93 \\
\hline 171660 & 3 & 77 & 70 & 93 \\
\hline 172675 & 23 & 70 & 87 & 93 \\
\hline 172677 & 20 & 53 & 83 & 87 \\
\hline 175563 & 23 & 77 & 67 & 97 \\
\hline 176383 & 0 & 43 & 77 & 83 \\
\hline 176384 & 13 & 63 & 97 & 97 \\
\hline 177239 & 13 & 63 & 87 & 83 \\
\hline 180017 & 0 & 67 & 87 & 87 \\
\hline 180044 & 13 & 60 & 53 & 73 \\
\hline 182129 & 37 & 70 & 90 & 90 \\
\hline 182130 & 33 & 73 & 93 & 77 \\
\hline 183010 & 20 & 80 & 83 & 83 \\
\hline 212586 & 30 & 77 & 87 & 83 \\
\hline 212878 & 30 & 70 & 100 & 100 \\
\hline 280063 & 23 & 60 & 87 & 93 \\
\hline 291124 & 23 & 77 & 100 & 100 \\
\hline 357993 & 0 & 93 & 23 & 47 \\
\hline 357997 & 0 & 93 & 77 & 90 \\
\hline 357998 & 0 & 70 & 13 & 43 \\
\hline 370030 & 53 & 80 & 83 & 73 \\
\hline Clemson Spineless & 27 & 63 & 70 & 83 \\
\hline Candelabra Branching & 10 & 80 & 70 & 70 \\
\hline Clemson Spineless $80^{\circ}$ & 3 & $\ldots z$ & 90 & $\ldots$ \\
\hline LSD 0.05 & 25 & 23 & 37 & 21 \\
\hline
\end{tabular}

${ }^{2}$ This cultivar was not tested at $15 / 15$ or $20 / 20 \mathrm{C}$

to $53 \%$ seedling emergence at $14 / 10 \mathrm{C}$ (Table 2). Only one genotype, PI 370030, exceeded $50 \%$ emergence, but it did not differ significantly from the nine PIs with emergence of $\geq 30 \%$ (Table 2). The $53 \%$ for this genotype represents an increase of $40 \%$ over the emergence at $10 / 10 \mathrm{C}$. Although most genotypes did not reach $50 \%$ emergence, differences were still detected among them. All seedlings showed poor growth, and their emerged cotyledons were chlorotic. In those genotypes that did emerge, true leaves failed to develop, and most had no lateral roots. Shoot and root length ranged from 0.9 to $2.2 \mathrm{~cm}$ and 1.0 to $3.1 \mathrm{~cm}$, respectively, but did not differ among genotypes.

Seedling emergence commenced at 6 days after planting at $15 / 15 \mathrm{C}$, and the seedlings were generally chlorotic. At 21 days, seedling emergence ranged from $43 \%$ to $93 \%$. The 21 genotypes with the highest percentage of emergence, ranging from 71 to 93, did not differ significantly (Table 2). These 21 genotypes included eight of the 10 with the highest percent emergence at 14/10C. At $15 / 15 \mathrm{C}$ all genotypes failed to produce first true leaves by 21 days, and the emerged cot-

Table 3. Seedling growth response of okra genotypes at 21 days after planting at three day/night temperature combinations.

\begin{tabular}{|c|c|c|c|c|c|c|c|}
\hline \multirow[b]{2}{*}{$\begin{array}{l}\text { PI no. or } \\
\text { cultivar }\end{array}$} & \multicolumn{2}{|c|}{$15 / 15 \mathrm{C}$} & \multicolumn{3}{|c|}{$20 / 10 \mathrm{C}$} & \multicolumn{2}{|c|}{$20 / 20 \mathrm{C}$} \\
\hline & $\begin{array}{l}\text { Shoot } \\
\text { length } \\
\text { (cm) }\end{array}$ & $\begin{array}{l}\text { Roots } \\
\text { (no.) }\end{array}$ & $\begin{array}{l}\text { Shoot } \\
\text { length } \\
\text { (cm) }\end{array}$ & $\begin{array}{l}\text { Roots } \\
\text { (no.) }\end{array}$ & $\begin{array}{l}\text { Shoot } \\
\text { dry wt } \\
\text { (g) }\end{array}$ & $\begin{array}{l}\text { Shoot } \\
\text { length } \\
\text { (cm) }\end{array}$ & $\begin{array}{l}\text { Roots } \\
\text { (no.) }\end{array}$ \\
\hline 120826 & 2.4 & 2 & 5.3 & 10 & 0.10 & 6.9 & 8 \\
\hline 120836 & 3.8 & 3 & 6.1 & 8 & 0.09 & 5.7 & 14 \\
\hline 120841 & 4.9 & 3 & 4.8 & 6 & 0.11 & 7.6 & 13 \\
\hline 124398 & 4.5 & 3 & 6.2 & 10 & 0.10 & 6.1 & 12 \\
\hline 127417 & 4.3 & 1 & 5.4 & 7 & 0.08 & 7.1 & 13 \\
\hline 138508 & 5.1 & 3 & 6.0 & 7 & 0.11 & 7.9 & 15 \\
\hline 140316 & 5.1 & 5 & 5.5 & 7 & 0.13 & 9.9 & 14 \\
\hline 142781 & 5.2 & 3 & 5.4 & 9 & 0.13 & 7.6 & 11 \\
\hline 142785 & 5.1 & 3 & 5.3 & 5 & 0.10 & 7.3 & 12 \\
\hline 167376 & 4.7 & 4 & 4.5 & 11 & 0.12 & 7.2 & 11 \\
\hline 169693 & 4.6 & 2 & 4.5 & 7 & 0.09 & 5.9 & 12 \\
\hline 169700 & 5.6 & 2 & 5.4 & 5 & 0.09 & 6.5 & 16 \\
\hline 169701 & 5.0 & 2 & 4.9 & 6 & 0.12 & 6.4 & 12 \\
\hline 169712 & 4.4 & 3 & 5.2 & 6 & 0.11 & 5.8 & 11 \\
\hline 171658 & 4.7 & 6 & 5.2 & 11 & 0.16 & 6.2 & 15 \\
\hline 171659 & 5.2 & 4 & 5.4 & 7 & 0.12 & 7.2 & 14 \\
\hline 171660 & 4.7 & 2 & 6.0 & 9 & 0.15 & 7.4 & 13 \\
\hline 172675 & 4.8 & 2 & 5.2 & 8 & 0.10 & 7.0 & 16 \\
\hline 172677 & 5.2 & 3 & 5.9 & 8 & 0.12 & 8.3 & 14 \\
\hline 175563 & 4.7 & 2 & 5.8 & 6 & 0.11 & 7.0 & 13 \\
\hline 176383 & 3.5 & 1 & 4.6 & 14 & 0.11 & 7.3 & 11 \\
\hline 176384 & 4.5 & 1 & 5.4 & 12 & 0.14 & 5.9 & 11 \\
\hline 177239 & 4.3 & 1 & 5.4 & 5 & 0.09 & 6.3 & 11 \\
\hline 180017 & 4.1 & 2 & 5.9 & 11 & 0.13 & 6.8 & 12 \\
\hline 180044 & 4.0 & 2 & 5.0 & 8 & 0.08 & 6.3 & 11 \\
\hline 182129 & 4.7 & 2 & 6.0 & 10 & 0.11 & 7.6 & 14 \\
\hline 182130 & 5.2 & 3 & 6.3 & 13 & 0.17 & 7.1 & 15 \\
\hline 183010 & 4.8 & 3 & 5.7 & 12 & 0.19 & 7.0 & 15 \\
\hline 212586 & 4.6 & 5 & 6.6 & 11 & 0.15 & 8.2 & 14 \\
\hline 212878 & 4.4 & 2 & 6.3 & 11 & 0.08 & 6.8 & 9 \\
\hline 280063 & 4.0 & 1 & 4.6 & 9 & 0.09 & 5.4 & 15 \\
\hline 291124 & 4.4 & 3 & 4.1 & 6 & 0.12 & 5.1 & 15 \\
\hline 357993 & 4.6 & 1 & 3.7 & 4 & 0.07 & 5.6 & 6 \\
\hline 357997 & 4.6 & 3 & 4.2 & 3 & 0.06 & 6.4 & 15 \\
\hline 357998 & 4.7 & 3 & 2.7 & 0 & 0.03 & 5.3 & 10 \\
\hline 370030 & 4.3 & 3 & 4.7 & 5 & 0.08 & 5.5 & 12 \\
\hline Clemson & & & & & & & \\
\hline Spineless & 4.4 & 1 & 5.7 & 9 & 0.09 & 6.4 & 12 \\
\hline Candelabra & & & & & & & \\
\hline Branching & 4.2 & 1 & 4.9 & 7 & 0.10 & 5.8 & 11 \\
\hline Clemson & & & & & & & \\
\hline Spineless 80 & $\ldots a^{2}$ & -- & 4.5 & 6 & 0.07 & $\cdots$ & $\cdots$ \\
\hline LSD 0.05 & 0.9 & 2 & 1.4 & 6 & 0.05 & 1.1 & 4 \\
\hline
\end{tabular}

${ }^{2}$ Not tested at $15 / 15$ or $20 / 20 \mathrm{C}$.

yledons were greenish yellow. The shoot length varied between 2.4 and $5.2 \mathrm{~cm}$ and the number of roots between one and six (Table 3).

Genotypes evaluated at 20/10C had emergence ranging from $13 \%$ to $100 \%$, with the top $33(64 \%$ to $100 \%)$ not differing significantly (Table 2). Some leaf chlorosis occurred at this temperature combination, probably due to the low night temperature. Genotypes did not differ significantly in the number of leaves per plant (zero to one per plant). Shoot length, shoot dry weight, and root count differed significantly among genotypes (Table 3), while the root length (3.3 to $9.4 \mathrm{~cm})$ and root dry weight $(0.01$ to $0.05 \mathrm{~g}$ ) did not.

At 20/20C, emergence began at 4 days after planting, with more than half of the genotypes attaining 50\% emergence in 7 days, and all genotypes, except PI 357993 and PI 357998, reaching 50\% within 12 days. Thirty genotypes had means ranging from $80 \%$ to $100 \%$ emergence (difference not significant)
(Table 2). Except for PIs 177239, 357993, and 357998, which failed to produce true leaves, the remaining genotypes produced one to two leaves per plant. As in the evaluations with nights at 10 and $15 \mathrm{C}$, seedling leaf chlorosis occurred but was not as severe as at the lower temperatures. Genotypes also varied in seedling shoot length and the number of roots produced (Table 3 ).

The results from these evaluations suggest that although $14 / 10 \mathrm{C}$ is too low for adequate emergence and early growth of okra, some genotypes will show differences in emergence but not in seedling growth. This lack of seedling growth is in agreement with the results of Sionit et al. (1981), who reported seedling death at 17 days after emergence for those at $17 / 11 \mathrm{C}$.

Although some okra seeds germinated and emerged at temperatures as low as $10 / 10 \mathrm{C}$, the seedlings were very chlorotic. At chilling night temperatures up to $15 \mathrm{C}$, variation in emergence existed and seedlings were chlorotic, with the degree of chlorosis decreasing 
with the increase in day temperature. Throughout the evaluations, PIs 138508, 169701 , and 370030 were consistently among the highest in emergence at the chilling night temperature of $15 \mathrm{C}$. Of the five temperature regimes, 20/10C was the only chilling combination that allowed okra genotypes to show variation in both emergence and shoot and root growth. Although emergence occurred at the lower temperature combinations, seedling shoot and root growth were retarded.

The inconsistent results of the field study show that okra seedling emergence, for genetic studies at least, should not be evaluated solely on the basis of field studies because the temperature variations from year to year cause inconsistent results. However, field results combined with controlled temperature evaluations can provide more meaningful results on chilling tolerance in okra seeds. Okra genotypes differ significantly in emergence with nights of $10 \mathrm{C}$, but seedlings will grow poorly unless the days are near $20 \mathrm{C}$.

\section{Literature Cited}

Buxton, D.R. and P.J. Sprenger. 1976. Genetic variability for cottonseed germination at favorable and low temperatures. Crop Sci. 16:243246.

Christiansen, M.N. 1963. Influence of chilling upon seedling development of cotton. Plant Physiol. 38:520-522.
Christiansen, M.N. 1967. Periods of sensitivity to chilling in germinating cotton. Plant Physiol. 42:431-433.

Herner, R.C. 1986. Germination under cold soil conditions. HortScience 21:1118-1122.

Omran, R.G. 1969. Chilling injury in okra and the relationship of chilling. PhD Diss., Texas A\&M Univ., (microfilm 69-14, 159, Univ. of Michigan, Ann Arbor).

Robbins, R. 1982. Guide to okra production. Amer. Veg. Grower 30(12):7-10.

Sionit, N., B.R. Strain, and H.A. Beckford. 1981. Environmental controls on the growth and yield of okra. I. Effects of temperature and of $\mathrm{CO}$ enrichment at cool temperatures. Crop Sci. 21:885-888 